\title{
Mediators of gender effects on depression among cardiovascular disease patients in Palestine
}

Hala Allabadi ${ }^{1,2,3^{*}}$, Nicole Probst-Hensch ${ }^{1,2}$, Abdulsalam Alkaiyat ${ }^{1,2,3}$, Saleem Haj-Yahia ${ }^{4,5,6}$, Christian Schindler ${ }^{1,2}$, Marek Kwiatkowski ${ }^{1,2}$ and Elisabeth Zemp ${ }^{1,2}$

\begin{abstract}
Background: Among patients suffering from coronary heart disease (CHD) and comorbid depression, women experience a higher burden compared to men. Little is known on the characteristics that differentiate men and women with both diseases and whether these factors mediate gender effects on depression. This study assessed whether women are more likely to suffer from depression and which characteristics mediate gender effects on depression among a cardiac population in Palestine, specifically addressing the role of post-traumatic stress disorder (PTSD).

Methods: Using a cross-sectional design, patients consecutively admitted with a CHD to one of the four main hospitals in Nablus, Palestine, were interviewed using a structured questionnaire with validated instruments. Data was also obtained from hospital medical records. Patients were assessed for depression using the Cardiac Depression Scale (CDS). Bivariate analysis was conducted to compare characteristics of women and men with and without depressive symptoms. Mediators (direct and indirect effects) of the association between gender and depression were evaluated using a structural equation model (SEM).

Results: Women were more likely to suffer from severe depression than men (28.7\% vs. 18.8\%). Female gender was positively associated with higher PTSD symptoms, comorbidities, somatic symptoms and income, and with lower resilience, self-esteem, quality of life, education, prevalence of smoking and physical activity. Structural equation modeling revealed negative indirect effects of gender on depression (CDS score) through resilience, self-esteem and physical activity, whereas positive indirect effects of gender on depression were observed through PTSD, comorbidities, somatic symptoms and smoking. There was no direct effect of gender on depression.

Conclusion: This study found a higher prevalence of severe depression in female patients with cardiac disease compared to male cardiac patients. Our findings provide novel information on mediating factors of the association between gender and depression among cardiac patients, in particular PTSD. The results emphasize the need for further research on potential mediating factors that could account for gender differences in depression and the need to provide support programs for female patients with comorbid CHD and depression to improve their psycho-social well-being.
\end{abstract}

Keywords: Gender, Depression, Cardiovascular disease, Mediators, Post-traumatic stress disorder

\footnotetext{
* Correspondence: hala.allabadi@swisstph.ch

${ }^{1}$ Department of Epidemiology and Public Health, Swiss Tropical and Public

Health Institute, Socinstrasse 57, P.O. Box, 4002, Basel, Switzerland

${ }^{2}$ University of Basel, Petersplatz 1, 4001 Basel, Switzerland

Full list of author information is available at the end of the article
}

(c) The Author(s). 2019 Open Access This article is distributed under the terms of the Creative Commons Attribution 4.0 International License (http://creativecommons.org/licenses/by/4.0/), which permits unrestricted use, distribution, and reproduction in any medium, provided you give appropriate credit to the original author(s) and the source, provide a link to the Creative Commons license, and indicate if changes were made. The Creative Commons Public Domain Dedication waiver (http://creativecommons.org/publicdomain/zero/1.0/) applies to the data made available in this article, unless otherwise stated. 


\section{Introduction}

Depression is an increasingly recognized risk factor for cardiovascular disease (CVD), particularly coronary heart disease (CHD) [1, 2]. The prevalence of depression among cardiac patients ranges from 15 to $30 \%$, which is considerably higher than in the general population [3]. Depression in cardiac patients is associated with poor outcomes [4], long-term prognosis [5], overall quality of life [6], mortality [1], and a dose-response relationship has been reported between depressive symptom level and subsequent mortality [7].

Depression is up to two times higher in women than in men $[8,9]$. Many factors could explain these differences including biological, genetic, psychological and social differences between women and men [10]. Gender and sex are often used interchangeably suggesting biological and psychosocial attributes vary with one another [11]. While sex denotes genetic and biological characteristics, gender refers to the array of socially constructed roles and relationships, personality traits, attitudes, behaviors and values that society ascribes to the sexes on a differential basis [12]. However, the use of the term sex as a 'stand-alone indicator of biology' is rejected as gendered experiences materialize in the body and measures of sex can include effects of gender [13]. In the case of depression and in the presence of sex differences, biology alone cannot provide an accurate explanation. Higher depression rates are found in women than men due to stressors related to social roles whereas lower rates of depression are found among men because male-attributed symptoms of depression such as anger, aggression, irritation, and abusive behavior are commonly not recognized as depressive symptoms [14]. Evidence suggests that women underprivileged in different aspects of life suffer from greater stressors and poorer health than men, including mental disorders and chronic diseases [15]. Women also report poorer health than men due to lack of access to healthcare and due to the stressors caused by their gender and marital roles [16, 17].

The role of gender for CHD has been addressed extensively in literature since the 1980's [6, 18]. Studies have reported that being female is associated with higher mortality and morbidity after cardiac events compared to being male $[19,20]$ and that women are likely to develop more depressive symptoms associated with $\mathrm{CHD}$ than men [21]. A meta-analysis found an overall prevalence of comorbid major depression of $18.7 \%$ in women compared to $12.0 \%$ in men. In particular, women are more vulnerable after coronary artery bypass graft (CABG) compared to men, suffer from more comorbid illness [22], are more likely to experience anxiety and more likely to be socially isolated [23]. Among myocardial infarction (MI) patients, women report less social support and more role disruption during recovery [24] and are two times more prone to depression post-MI than men [25]. Therefore, female cardiac patients have a higher risk of suffering from adverse effects of depression on the prognosis of their disease $[1,9,26]$. In addition, women have greater symptom frequency, experience greater risk of re-infarction, have lower survival rates after $C A B G$ and higher rates of subsequent heart failure (HF) compared to men [27-29]. In several studies, the worse cardiac outcomes in women persist after adjustment for age, medical history, clinical severity, hospital treatment, and cardiac procedures [28, 30-32]. Despite the burden observed in women due to comorbid CHD and depression, they continue to be understudied in research and data are often not presented by gender. The high burden of CVD and the rise of depression rates among women in the general population as well as in CHD populations call for assessment of the gender gap in depression. There is scarce literature on characteristics that distinguish men and women with comorbid $\mathrm{CHD}$ and depression. Furthermore, whether these factors mediate gender effects on depression in cardiac patients remains unclear. This ultimately makes it difficult to identify women at higher risk of adverse outcomes associated with both CHD and depression. In this paper, the terms sex and gender as well as women and men are used: 'gender' as an overarching notion; 'sex' when referring to associations reported in the literature for being female and male respectively; and the terms 'women' and 'men' to denote population subgroups.

Post-traumatic stress disorder (PTSD) is also a common co-morbid condition in cardiac patients [33] and rates are higher among female cardiac patients. PTSD has been associated with recurrent MI, hospitalizations and mortality [34, 35]. Similarly, PTSD exhibits genderspecific patterns and is known to be comorbid with depression [36].

Previous literature has focused on gender differences in depression among heart disease patients mainly in high income countries [18, 27]. In Middle Eastern countries, CVD accounts for $34 \%$ of all deaths and PTSD is high among individuals living in regions of conflict [37]. The Occupied Palestinian Territories (oPt) in particular, report high rates of depression in response to the stressful living conditions. The different societal roles of women and the evidence based CVD-gender differences call for more research into the understanding of gender-related factors with regard to depression and mediating factors among cardiac patients. In this study, we sought to assess whether Palestinian women are more likely to suffer from depression than Palestinian men among a sample of 1022 consecutively admitted cardiac patients at one of the four major hospitals in the West Bank city of Nablus, Palestine, and to investigate whether socio- 
demographic, clinical, psychosocial and lifestyle characteristics mediate gender effects on depression, especially addressing the role of PTSD.

\section{Methods}

\section{Study design and population}

This cross-sectional hospital-based study was conducted on consecutive patients aged 30-80 years admitted to the cardiology and cardiac surgery departments at one of the four main hospitals in Nablus, Palestine, during their stay in the hospital (1-7 days) between March 2017 and November 2017. They were included in the study if they were diagnosed with CHD, ST elevation or non-ST elevation MI, angina, HF, cardiac arrhythmia, valve disease or any other cardiac disease. Patients with a normal cardiac catheterization (CATH), an acute or past stroke, end-stage kidney disease (including dialysis patients), peripheral vascular disease, psychological disorders, cognitive deficit, neurological disorders (dementia, Alzheimer's disease, epilepsy, Parkinson's disease), use of antidepressant or any other condition affecting the quality of their responses were excluded from the study. A total of 1092 patients were approached and met initial eligibility requirements, and 1053 agreed to participate in the study. The analytic sample included 1022 subjects. The study was approved by the Ethics Committee of Nordwest-und Zentral Schweiz (EKNZ) in Basel, Switzerland, and by the Institutional Review Board (IRB) committee at An-Najah National University in Nablus, Palestine.

\section{Data collection}

Eligible patients were approached for private in-person interviews using hospital registries and written informed consent was obtained from those who agreed to participate. Prior to completion of the interview, socio-demographic and clinical characteristics including: age, gender, marital status, residence, education level, occupation, income; current diagnosis, previous cardiac diagnoses, years with cardiac disease, cardiac treatment (at admission), co-morbidities, medications and family history of CVD were retrieved from patients' medical records and were ascertained via patient interview. Inperson interviews consisted of a sequence of validated instruments assessing physical and psychosocial factors and questions assessing lifestyle factors.

\section{Study measurements}

Depressive symptoms were assessed by the Cardiac Depression Scale (CDS), a disease-specific, 26-item questionnaire used to accurately measure depression in patients with CVD. The CDS is scored based on a Likert scale ranging from strongly disagree (1) to strongly agree (7). Total scores are calculated as the sum of the scores of each item and range from 26 to 182 [38]. The CDS can be used as a continuous measure, where higher scores indicate more severe depressive symptoms, or as an ordinal indicator of possible depression using previously established cut-off points which include: $<90$ for no depression; 90-100 for mild to moderate depression; and $>100$ for severe depression. These cut offs were used in the current study to categorize depressive symptoms. The CDS has a sensitivity of $88 \%$ and a specificity of $84 \%$ for severe depression when a cutoff of $>100$ is used, and $84 \%$ sensitivity and $78 \%$ specificity for cutoff scores of 90-100 [39]. Further instruments used include the Post-Traumatic Stress Disorder Checklist (PTSD-PCL-S) [40]; Enhancing Recovery in Coronary Heart Social Support Instrument (ESSI) [41, 42]; Resilience Scale-14 (RS14) [43]; Single-Item Self-Esteem Scale (SISE) [44]; Short-form 12 Health Survey (SF-12-PCS; SF-12-MCS) [45] and the Patient Health Questionnaire-15 (PHQ-15) [46]. The instruments have been described in detail elsewhere [47].

\section{Statistical analyses}

Depressive symptoms were examined both as a continuous variable (CDS score) and as a dichotomous variable (presence of moderate-severe depressive symptoms using the standard cutoff of CDS $\geq 90$ ). Characteristics of women and men with and without depressive symptoms were compared using Chi-squared or Fisher exact tests for categorical variables, and independent $t$-tests for continuous variables, as appropriate.

A structural equation model (SEM) was built to assess direct and indirect (i.e. mediated) effects of gender on depression. Mediators are variables which transfer part of the effect of an independent variable (IV) on a dependent variable (DV). In our analysis, the IV was gender (used as a binary variable, with "being female" coded as 1), the DV was depression (CDS score, used as a continuous variable), and the potential mediator variables were sociodemographic, clinical, psychosocial and lifestyle factors [48]. First, mediator groups (i.e. socio-demographic, clinical, psychosocial and lifestyle factors) were assessed in separate models. In a second step, the final model was built (reference model, $N=1022$ ), including education, income, comorbidities, somatic symptoms, quality of life, PTSD, resilience, self-esteem, smoking, physical activity. These potential mediators were chosen based on 1) their statistical significance in the preceding analyses, using a cut-off level of $p<0.102$ ) the magnitude of their association 3) whether the associations were significant between gender and the potential mediator, as well as between the potential mediator and depression (CDS score). The SEM was estimated using the maximum likelihood method and included continuous, binary and ordinal variables which were all treated as continuous. Inclusion of a larger 
number of potential mediators reduces bias in estimating the true direct effect of gender on depression (CDS score). Potential confounding factors assessed were age, marital status, occupation, social support, and lifestyle factors (i.e. BMI, alcohol consumption). A further SEM-analysis was then conducted stratifying by age, running separate models for two age groups (those aged below and above the median age of 59 years; see Additional file 1: Figure S1a and $\mathrm{b}$ ). Moderation by age was assessed by testing the differences between corresponding age-specific effects using Chi-squared tests. In further analyses, two additional SEM's were computed to assess whether resilience and smoking could be potential mediators and/or moderators of the effect of PTSD on depression, adding the respective factor as mediator between PTSD and depression and testing its interaction with PTSD to assess potential moderation. This additional analysis was based on general conceptualization and literature on psychological comorbidity of PTSD and depression [36, 49]. Analysis was conducted using the STATA Statistical Software Release 15 (StataCorp., College Station, U.S.A.).

\section{Results}

This sample consisted of $750(73.4 \%)$ men and 272 (26.6\%) women. Among the cardiac patients with depressive symptoms, 231 (28.7\%) were women. In contrast, among patients without depressive symptoms, 41 $(18.8 \%)$ were women. Socio-demographic, clinical, psychosocial and lifestyle factors of depressed and non-depressed men and women are presented in Table 1 . In terms of socio-demographic factors, among those with depressive symptoms, women were on average older than men, more likely to be unmarried (i.e. single, widowed), less educated, unemployed and have no income compared to men.

Differences among women and men with depressive symptoms in terms of clinical factors were also found. Women with depressive symptoms were more likely to have a severe cardiac disease (i.e. heart failure, mitral or aortic valve stenosis) compared to men with depressive symptoms who had mostly CHD or a MI diagnosis, more likely to report a previous cardiac diagnosis, undergo a $\mathrm{CATH} / \mathrm{complex}$ procedure (i.e. valve replacement), have two or more comorbid conditions (i.e. diabetes, hypertension, the combination of both), take three to four medications, have higher somatic symptoms and to score lower on the SF-12-PCS for quality of life.

Bivariate comparisons of psychosocial factors between depressed men and women revealed that depressed women were more likely to have higher levels of PTSD symptoms, lower social support, lower resilience, lower self-esteem and a lower score on the SF-12-MCS for quality of life than their male counterparts.
Regarding lifestyle factors, women with depressive symptoms were less likely to be smokers and have a high fat intake, while more likely to be physically inactive and to be obese than men with depressive symptoms.

In the sample without depressive symptoms, the pattern of gender differences was similar, but with the small sample of women without depression $(n=41)$, significant differences were observed less frequently.

The presence of depressive symptoms as defined by a CDS score $\geq 90$ among the total sample was $78.7 \%$. The proportion of severe depressive symptoms $(\mathrm{CDS}>100)$ was higher in women compared to men $(61.4 \%$ versus $50.7 \%, P=0.003$ ), while the proportion of women without depressive symptoms was $15.1 \%$ versus $23.6 \%$ for men (Table 2). Comparison of depressive and PTSD symptoms assessed as continuous variables (means of CDS and PTSD scores) by gender revealed that women had significantly higher CDS $(104.6 \pm 15.9 ; t=4.1 ; P<0.001)$ and PTSD scores (29.4 $\pm 10.6 ; t=4.4 ; P<0.001)$ (Fig. 1$)$.

\section{Direct and indirect effects of gender on depression (CDS score)}

The pooled SEM of the direct effect of gender on depression (CDS score) and the indirect effects when mediators were added was conducted for the overall sample. Figure 2 illustrates the pathways between gender and depression with the tested mediators. Parameters reported in the figure include coefficients and confidence intervals (CI). They demonstrate the associations of gender with each potential mediating factor and between each potential mediating factor and outcome variable, after adjusting for the effect of gender. Results from the SEM showed both positive and negative mediators, where positive mediators mediating the gender difference on depression are associated both with being female and higher levels of depression. In the pooled SEM of gender and depression, there was no direct effect of gender on CDS score (coefficient: 0.0, 95\% CI: - 2.2-2.2, $p=1.0)$. There were significant direct effects of gender on the mediators as shown in Fig. 2. On the one hand, female gender was positively associated with higher PTSD symptoms, comorbidities, somatic symptoms and income. On the other hand, female gender was associated with lower resilience, self-esteem, quality of life, education, less smoking and lower physical activity. Negative indirect effects of gender on depression were observed through resilience, self-esteem, quality of life, (SF-12-PCS), education, income and physical activity, whereas positive indirect effects of gender on depression were observed through PTSD, comorbidities, somatic symptoms, and smoking. Quality of life, education, and income were not significant mediators for the indirect effect of gender on depression. No evidence of moderation was found for the direct effect of gender on CDS 
Table 1 Bivariate comparison of study characteristics in men and women with CVD, by presence and absence of depressive symptoms, $N=1022$

\begin{tabular}{|c|c|c|c|c|c|c|}
\hline \multirow[t]{2}{*}{ Variable } & \multicolumn{3}{|c|}{$\begin{array}{l}\text { Sample with depressive Symptoms (CDS } \geq 90) \\
(N=804)\end{array}$} & \multicolumn{3}{|c|}{$\begin{array}{l}\text { Sample without depressive symptoms }(C D S<90) \\
(N=218)\end{array}$} \\
\hline & $\begin{array}{l}\text { Male } \\
(N=573) N(\%)\end{array}$ & $\begin{array}{l}\text { Female } \\
(N=231) N(\%)\end{array}$ & $P$ value & $\begin{array}{l}\text { Male } \\
(N=177) N(\%)\end{array}$ & $\begin{array}{l}\text { Female } \\
(N=41) N(\%)\end{array}$ & $P$ value \\
\hline \multicolumn{7}{|l|}{ Socio-demographic factors } \\
\hline Age, mean $(S D)^{a}$ & $57.9 \pm 9.6$ & $61.6 \pm 10.5$ & $<0.001$ & $57.8 \pm 10.2$ & $63.7 \pm 10.7$ & 0.001 \\
\hline Marital status & & & $<0.001$ & & & $<0.001$ \\
\hline Married & $564(98.4)$ & $171(74.0)$ & & $166(93.8)$ & $25(60.7)$ & \\
\hline Not married & $9(1.6)$ & $60(26.0)$ & & $11(6.2)$ & $16(39.0)$ & \\
\hline Residence & & & 0.456 & & & 0.723 \\
\hline City & $261(45.5)$ & $104(45.0)$ & & $89(50.3)$ & $20(48.8)$ & \\
\hline Village & $270(47.1)$ & $104(45.0)$ & & $79(44.6)$ & $20(48.8)$ & \\
\hline Camp & $42(7.3)$ & $23(10.0)$ & & $9(5.1)$ & $1(2.4)$ & \\
\hline Education degree & & & $<0.001$ & & & 0.004 \\
\hline No HS diploma & $298(52.0)$ & $188(81.4)$ & & $84(47.4)$ & $30(73.2)$ & \\
\hline HS diploma & $173(30.2)$ & $32(13.8)$ & & $49(27.7)$ & $9(21.9)$ & \\
\hline College degree & $102(17.8)$ & $11(4.8)$ & & $44(24.9)$ & $2(4.9)$ & \\
\hline Occupation & & & $<0.001$ & & & $<0.001$ \\
\hline Professional & $153(26.7)$ & $9(3.9)$ & & $47(26.6)$ & $0(0.0)$ & \\
\hline Non-professional & $226(39.4)$ & $4(1.7)$ & & $76(42.9)$ & $1(2.4)$ & \\
\hline Unemployed & $143(25.0)$ & $175(75.8)$ & & $31(17.5)$ & $29(70.8)$ & \\
\hline Retired & $51(8.9)$ & $4(1.7)$ & & $23(13.0)$ & $3(7.3)$ & \\
\hline House wife & $0(0.0)$ & 39 (16.9) & & $0(0.0)$ & $8(19.5)$ & \\
\hline Income & & & $<0.001$ & & & $<0.001$ \\
\hline Yes & $442(77.1)$ & 77 (33.3) & & $146(82.5)$ & $12(29.3)$ & \\
\hline No & $131(22.9)$ & $154(66.7)$ & & $31(17.5)$ & $29(70.7)$ & \\
\hline \multicolumn{7}{|l|}{ Clinical Factors } \\
\hline Cardiac diagnosis & & & $<0.001$ & & & 0.010 \\
\hline $\mathrm{CHD}$ & $188(32.8)$ & $63(27.3)$ & & $70(39.6)$ & $13(31.7)$ & \\
\hline $\mathrm{Ml}$ & $242(42.2)$ & $76(32.9)$ & & $73(41.2)$ & 15 (36.6) & \\
\hline Angina & $96(16.8)$ & $38(16.4)$ & & $24(13.6)$ & $4(9.8)$ & \\
\hline Other & $47(8.2)$ & $54(23.4)$ & & $10(5.6)$ & $9(21.9)$ & \\
\hline Previous cardiac diagnosis & & & 0.036 & & & 0.898 \\
\hline Yes & $386(67.4)$ & $173(74.9)$ & & $106(59.9)$ & $25(61.0)$ & \\
\hline No & $187(32.6)$ & $58(25.1)$ & & $71(40.1)$ & $16(39.0)$ & \\
\hline Years with cardiac disease & & & 0.356 & & & 0.800 \\
\hline$\leq 1$ year & $347(60.6)$ & $130(56.3)$ & & $124(70.1)$ & $27(65.8)$ & \\
\hline 2-9years & $148(25.8)$ & $61(26.4)$ & & $37(20.9)$ & $9(22.0)$ & \\
\hline$\geq 10$ years & 78 (13.6) & $40(17.3)$ & & $16(9.0)$ & $5(12.2)$ & \\
\hline Cardiac treatment (at admission) & & & 0.005 & & & 0.872 \\
\hline CATH/stent & $306(53.4)$ & $98(42.4)$ & & $107(60.5)$ & $23(56.0)$ & \\
\hline $\mathrm{CATH} / \mathrm{CABG}$ & $139(24.3)$ & $58(25.1)$ & & $34(19.2)$ & $9(22.0)$ & \\
\hline CATH/other \& unknown & $128(22.3)$ & $75(32.5)$ & & $36(20.3)$ & $9(22.0)$ & \\
\hline Co-morbidities & & & $<0.001$ & & & 0.021 \\
\hline None & $182(31.8)$ & $32(13.9)$ & & $73(41.2)$ & $12(29.3)$ & \\
\hline
\end{tabular}


Table 1 Bivariate comparison of study characteristics in men and women with CVD, by presence and absence of depressive symptoms, $N=1022$ (Continued)

\begin{tabular}{|c|c|c|c|c|c|c|}
\hline \multirow[t]{2}{*}{ Variable } & \multicolumn{3}{|c|}{$\begin{array}{l}\text { Sample with depressive Symptoms (CDS } \geq 90) \\
(N=804)\end{array}$} & \multicolumn{3}{|c|}{$\begin{array}{l}\text { Sample without depressive symptoms }(C D S<90) \\
(N=218)\end{array}$} \\
\hline & $\begin{array}{l}\text { Male } \\
(N=573) N(\%)\end{array}$ & $\begin{array}{l}\text { Female } \\
(N=231) N(\%)\end{array}$ & $P$ value & $\begin{array}{l}\text { Male } \\
(N=177) N(\%)\end{array}$ & $\begin{array}{l}\text { Female } \\
(N=41) N(\%)\end{array}$ & $P$ value \\
\hline 1 & $169(29.5)$ & $68(29.4)$ & & $57(32.2)$ & $9(22.0)$ & \\
\hline $2+$ & $222(38.7)$ & $131(56.7)$ & & $47(26.6)$ & $20(48.7)$ & \\
\hline Medications & & & 0.003 & & & 0.471 \\
\hline None & $81(14.1)$ & $13(5.6)$ & & $32(18.1)$ & $6(14.6)$ & \\
\hline $1-2$ & $85(14.9)$ & $37(16.0)$ & & $22(12.4)$ & $8(19.5)$ & \\
\hline $3-4$ & $407(71.0)$ & $181(78.4)$ & & $123(69.5)$ & $27(65.8)$ & \\
\hline Somatic symptoms (PHQ-15) & & & $<0.001$ & & & 0.046 \\
\hline Minimal & $48(8.4)$ & $6(2.6)$ & & $35(19.8)$ & $2(4.9)$ & \\
\hline Low & $118(20.6)$ & $34(14.7)$ & & $74(41.8)$ & $15(36.6)$ & \\
\hline Medium & $193(33.7)$ & $64(27.7)$ & & $43(24.3)$ & $14(34.1)$ & \\
\hline High & $214(37.3)$ & $127(55.0)$ & & $25(14.1)$ & $10(24.4)$ & \\
\hline Family history & & & 0.356 & & & 0.033 \\
\hline Yes & $236(41.2)$ & $87(37.7)$ & & $63(35.6)$ & $22(53.7)$ & \\
\hline No & $337(58.8)$ & $144(62.3)$ & & $114(64.4)$ & $19(46.3)$ & \\
\hline QoL, (SF-12-PCS score), mean (SD) & $38.2 \pm 12.1$ & $31.4 \pm 10.1$ & $<0.001$ & $44.6 \pm 12.1$ & $34.4 \pm 1.9$ & $<0.001$ \\
\hline \multicolumn{7}{|l|}{ Psychosocial factors } \\
\hline PTSD (PTSD-PCL-S) & & & $<0.001$ & & & 0.282 \\
\hline Minimal & $329(57.4)$ & $105(45.4)$ & & $147(83.1)$ & $30(73.2)$ & \\
\hline Some & $66(11.5)$ & $15(6.5)$ & & $11(6.2)$ & $3(7.3)$ & \\
\hline Moderate & $141(24.6)$ & $85(36.8)$ & & $19(10.7)$ & $8(19.5)$ & \\
\hline High & $37(6.5)$ & $26(11.3)$ & & $0(0.0)$ & $0(0.0)$ & \\
\hline Social support (ESSI) & & & $<0.001$ & & & 0.293 \\
\hline Low & $186(32.5)$ & $108(46.7)$ & & $54(30.5)$ & $16(39.0)$ & \\
\hline High & $387(67.5)$ & $123(53.3)$ & & $123(69.5)$ & $25(61.0)$ & \\
\hline Resilience (RS-14) & & & $<0.001$ & & & 0.002 \\
\hline Very low & $45(7.9)$ & $38(16.4)$ & & $3(1.7)$ & $6(14.6)$ & \\
\hline Low & $55(9.6)$ & $38(16.4)$ & & $8(4.5)$ & $2(4.9)$ & \\
\hline Low-end & $118(20.6)$ & $46(19.9)$ & & $37(20.9)$ & $3(7.3)$ & \\
\hline Moderate & $148(25.8)$ & $52(22.5)$ & & $45(25.4)$ & $12(29.3)$ & \\
\hline Moderately-high & $156(27.2)$ & $45(19.5)$ & & $58(32.8)$ & $15(36.6)$ & \\
\hline High & $51(8.9)$ & $12(5.1)$ & & $26(14.7)$ & $3(7.3)$ & \\
\hline Self-esteem (SISE), mean (SD) ${ }^{a}$ & $5.9 \pm 1.3$ & $5.2 \pm 1.6$ & $<0.001$ & $6.2 \pm 1.0$ & $6.1 \pm 1.2$ & 0.633 \\
\hline QoL,(SF-12-MCS score), mean (SD) & $39.1 \pm 12.5$ & $35.3 \pm 3.3$ & $<0.001$ & $46.2 \pm 12.6$ & $47.0 \pm 1.9$ & 0.724 \\
\hline \multicolumn{7}{|l|}{ Lifestyle factors } \\
\hline Smoking status & & & $<0.001$ & & & $<0.001$ \\
\hline Never & $106(18.5)$ & $182(78.8)$ & & $42(23.7)$ & $34(82.9)$ & \\
\hline Former & $126(22.0)$ & $11(4.8)$ & & $105(59.3)$ & $4(9.8)$ & \\
\hline Current & $341(59.5)$ & $38(16.4)$ & & $30(17.0)$ & $3(7.3)$ & \\
\hline Currently on diet & & & 0.767 & & & 0.483 \\
\hline Yes & $87(15.2)$ & $37(16.0)$ & & $39(22.0)$ & $7(17.1)$ & \\
\hline No & $486(84.8)$ & $194(84.0)$ & & $138(78.0)$ & $34(82.9)$ & \\
\hline
\end{tabular}


Table 1 Bivariate comparison of study characteristics in men and women with CVD, by presence and absence of depressive symptoms, $N=1022$ (Continued)

\begin{tabular}{|c|c|c|c|c|c|c|}
\hline \multirow[t]{2}{*}{ Variable } & \multicolumn{3}{|c|}{$\begin{array}{l}\text { Sample with depressive Symptoms (CDS } \geq 90) \\
(N=804)\end{array}$} & \multicolumn{3}{|c|}{$\begin{array}{l}\text { Sample without depressive symptoms }(C D S<90) \\
(N=218)\end{array}$} \\
\hline & $\begin{array}{l}\text { Male } \\
(N=573) N(\%)\end{array}$ & $\begin{array}{l}\text { Female } \\
(N=231) N(\%)\end{array}$ & $P$ value & $\begin{array}{l}\text { Male } \\
(N=177) N(\%)\end{array}$ & $\begin{array}{l}\text { Female } \\
(N=41) N(\%)\end{array}$ & $P$ value \\
\hline Fat consumption & & & $<0.001$ & & & 0.075 \\
\hline Low & $247(43.1)$ & $127(55.0)$ & & $85(48.0)$ & $21(51.2)$ & \\
\hline Medium & $176(30.7)$ & $77(33.3)$ & & $53(30.0)$ & $17(41.5)$ & \\
\hline High & $150(26.2)$ & $27(11.7)$ & & $39(22.0)$ & $3(7.3)$ & \\
\hline Vegetable \& fruit consumption & & & 0.920 & & & 0.789 \\
\hline Low & $59(10.3)$ & $25(10.8)$ & & $15(8.5)$ & $3(7.3)$ & \\
\hline Medium & $200(34.9)$ & $83(35.9)$ & & $55(31.1)$ & $15(36.6)$ & \\
\hline High & $314(54.8)$ & $123(53.3)$ & & $107(60.4)$ & $23(56.1)$ & \\
\hline Alcohol use & & & 0.004 & & & 0.100 \\
\hline Yes & $35(6.1)$ & $3(1.3)$ & & $11(6.2)$ & $0(0.0)$ & \\
\hline No & $536(93.9)$ & $228(98.7)$ & & $165(93.8)$ & $41(100.0)$ & \\
\hline Physical activity & & & $<0.001$ & & & 0.008 \\
\hline None & $178(31.1)$ & $117(50.7)$ & & $31(17.5)$ & $11(26.8)$ & \\
\hline Not daily & $116(20.2)$ & $37(16.0)$ & & $24(13.6)$ & $12(29.3)$ & \\
\hline Daily & $279(48.7)$ & $77(33.3)$ & & $122(68.9)$ & $18(43.9)$ & \\
\hline BMl & & & 0.083 & & & 0.230 \\
\hline Underweight & $3(0.5)$ & $0(0.0)$ & & $1(0.6)$ & $0(0.0)$ & \\
\hline Normal weight & 118 (20.6) & 39 (16.9) & & $38(21.5)$ & $4(9.8)$ & \\
\hline Overweight & $236(41.2)$ & $84(36.4)$ & & $87(49.1)$ & $20(48.8)$ & \\
\hline Obese & $216(37.7)$ & $108(46.7)$ & & $51(28.8)$ & $17(41.4)$ & \\
\hline
\end{tabular}

Gender differences were assessed using Chi-squared and t-tests, respectively, both in patients with and without depressive symptoms

$P$ values in bold are significant at $p<0.05$

CDS Cardiac depression scale, HS High school, MI Myocardial infarction, CHD Coronary heart disease, CATH Catheterization, CABG Coronary artery bypass graft, PHQ-15 Patient health questionnair-15, QoL Quality of life, SF-12 Short-form 12 health survey, PCS Physical component summary, SD Standard deviation, PTSD Post-traumatic stress disorder, PTSD-PCL-S Post-traumatic stress disorder checklist, RS-14 Resilience scale-14, SISE Single-item self-esteem scale, ESSI ENRICHD social support instrument, MCS Mental component summary, BMI Body mass index

${ }^{a}$ Independent $t$ test

score, the effects of gender on mediators and the effects of mediators on CDS score.

There was no indication of confounding or moderation by age. In the pooled model, age was not significant when a direct effect of age on CDS score was added to the model. There were also no significant differences between corresponding effect estimates after SEM's were conducted separately for the two age groups $<59$ years and $\geq 59$ years. These results are presented in Additional file 1: Figure S1a and b.
The SEM conducted to assess whether resilience could also be a mediator and/or moderator between PTSD and depression (CDS score) revealed a significant direct association between PTSD and depression and a small positive moderating effect of resilience on this association was observed. There were negative yet significant associations between PTSD and resilience and between resilience and depression (see Additional file 2: Figure S2). Thus, in this SEM, resilience appeared both as a mediator of the total effect of

Table 2 Frequency of levels of severity of depressive symptoms, by gender

\begin{tabular}{llll}
\hline CDS score & $\begin{array}{l}\text { Total Population } \\
(N=1022)\end{array}$ & $\begin{array}{l}\text { Men value } \\
(N=750)\end{array}$ & $\begin{array}{l}\text { Women } \\
(N=272)\end{array}$ \\
\hline$<90:$ no depression & $218(21.3)$ & $177(23.6)$ & 0.003 \\
$90-100:$ mild to moderate depression & $257(25.2)$ & $193(25.7)$ & $64(23.5)$ \\
$>100:$ severe depression & $547(53.5)$ & $380(50.7)$ & $167(61.4)$
\end{tabular}




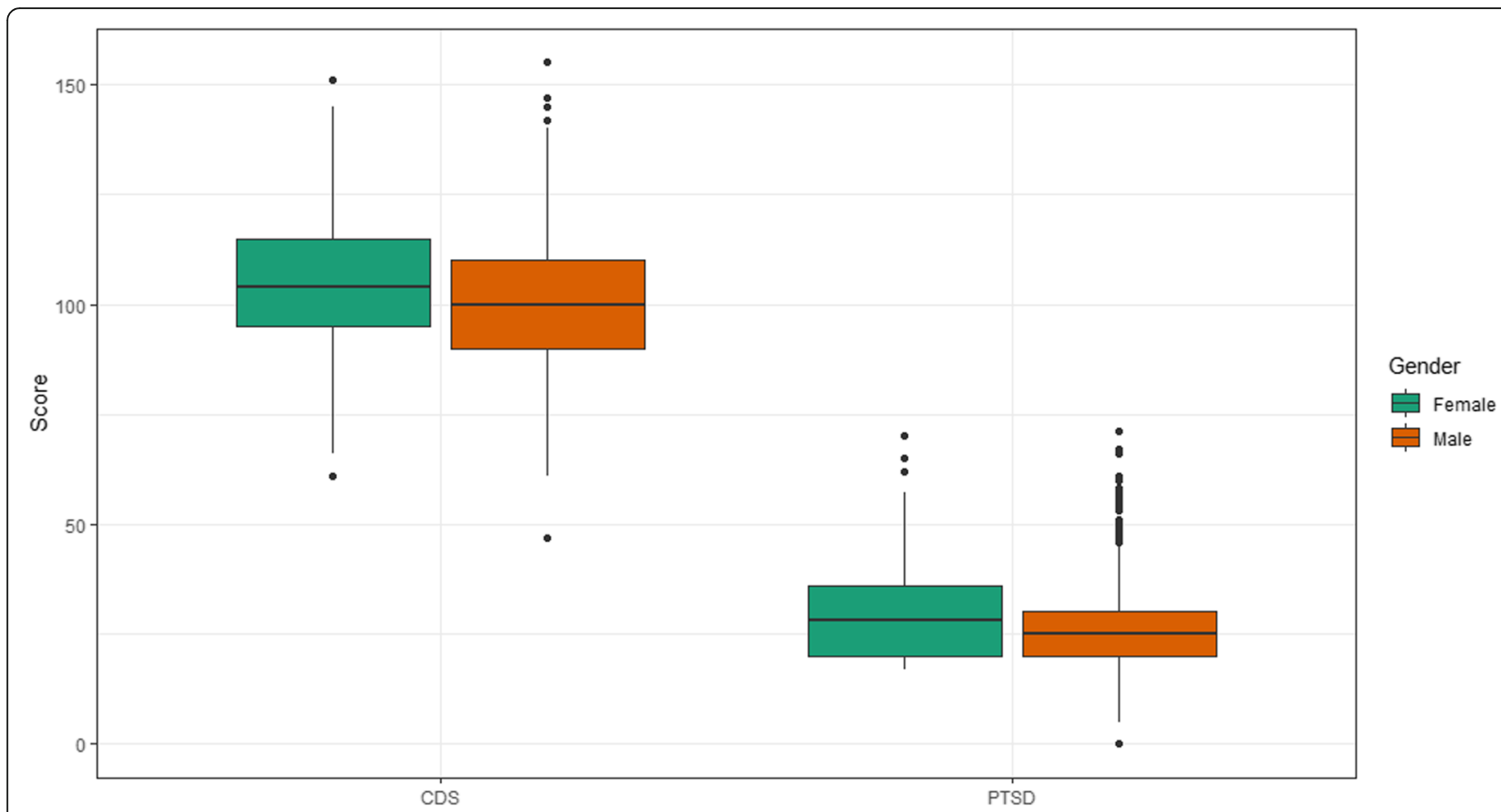

Fig. 1 Distribution of scores for symptoms of depression (CDS score) and PTSD score, by gender. Note. CDS=Cardiac Depression Scale (Possible score range: 26-182; Actual score range: 47-155); PTSD = Post-traumatic Stress Disorder (Possible score range: 0-85; Actual score range: 0-71)

PTSD on depression and a moderator of the respective direct effect.

Figure 3 illustrates the interaction between PTSD and resilience, in which the difference in predicted depression (CDS score) between those with low and high resilience decreases slightly with increasing PTSD symptoms. This suggests that resilience shows a clearer protective role at lower levels of PTSD, becoming less protective at higher levels of PTSD.

No mediation by smoking of the association between PTSD and depression (CDS score) was found (data not shown).

\section{Discussion}

In our sample of cardiac patients, women with CVD have a higher prevalence of severe depressive symptoms (61.4\%) compared to men (50.7\%). The association of gender with depression was entirely explained by a number of mediators. The strongest positive mediator was PTSD, which was more prevalent in women and positively associated with depression. While resilience itself was a negative mediator of the gender-depression association, it mediated and moderated the PTSD-depression (CDS score) association. Besides mediation by psychosocial parameters, lifestyle factors such as physical activity and smoking also explained part of the genderdepression association.

Our findings that women with CVD were more likely to experience depressive symptoms and at higher levels than men with CVD were consistent with other studies [50-52]. This finding is also consistent with the respective sex difference observed in the general population [9].

Previously, there has been evidence on gender being linked to PTSD and comorbid depression as well as PTSD and associated outcomes in cardiac patients. However, to our knowledge, this is the first study to assess direct and indirect effects of gender on depression among a cardiac population, with a particular focus on PTSD as a mediator. Previous studies have found that women are at higher risk of comorbid PTSD and depression symptoms compared to men [53, 54], similar to our findings which showed a direct significant association of female gender with PTSD and a significant indirect effect of gender on depression mediated by PTSD. Reasons for these gender differences could be attributed to the different types of traumatic or stressful situations which men and women are exposed to, different responses to trauma, and different symptom-related responses, all of which may affect the course and severity of symptoms [55]. In addition, higher rates of PTSD and depression among women could be due to women's lower social position which can lead to greater exposure to trauma and stressors compared to men [56]. This could particularly be true among our sample and in the cultural context of Palestine, where women have much lower social positions compared to men. In the present study, women had more severe diagnoses, comorbidities and complicated treatment procedures along with other 


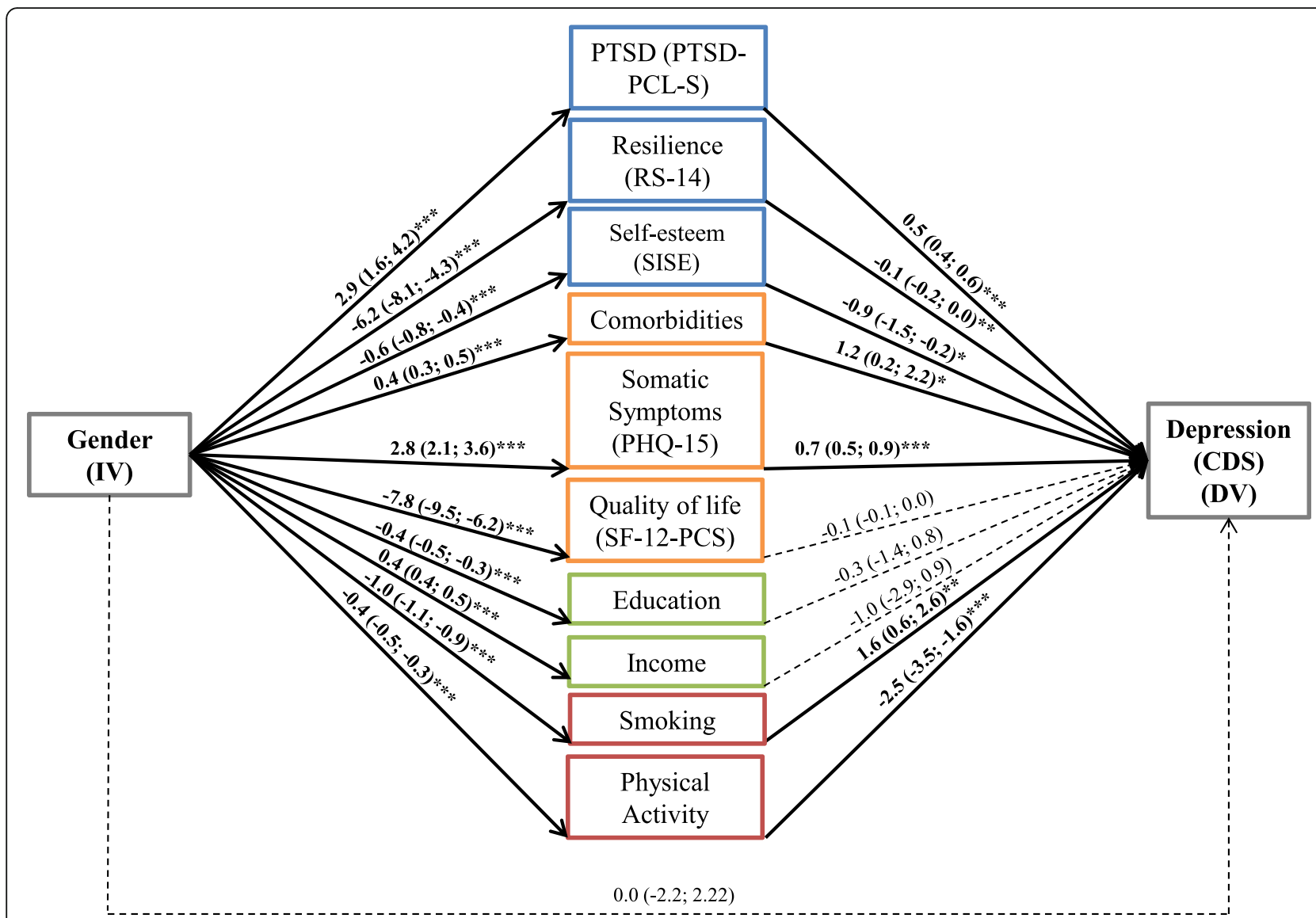

Fig. 2 SEM of the direct and indirect effects of gender on depression (CDS score), ( $N=1022)$. Note. The pathways represented by arrows correspond to direct and indirect effects of gender on depression (CDS score). Solid arrows (in bold) represent statistically significant associations between variables and dashed arrows represent non-significant associations. Each arrow is labeled with the respective effect estimate and its 95\%-confidence interval. The effect magnitudes on the arrows are not comparable to each other because the mediators have different scale ranges.Gender was coded as $0=$ male, 1 = female; IV = independent variable, DV = dependent variable, CDS=Cardiac Depression Scale, PTSD-PCLS=Post-traumatic Stress Disorder Checklist, RS-14 = Resilience Scale-14, SISE = Single-ltem Self-Esteem Scale, SF-12-PCS = Short-form 12 Health Survey-Physical Component Summary, PHQ-15 = the Patient Health Questionnaire-15; ${ }^{*} p<0.05,{ }^{* *} p<0.01,{ }^{* *} p<0.001$

negative daily stressors, suggesting that women were more vulnerable to traumatic stress which arises from both PTSD and depression and their comorbidity. Dao et al., found increased mortality among comorbid PTSD and depression patients after CABG to be linked to female gender [49]. These results have implications for early assessment of these mental health disorders, as their comorbidity is becoming more frequently observed and prevalent in cardiac patients.

Our findings also reveal that low resilience is associated with being female and higher depressive symptoms among our cardiac sample. This finding supports the results of a study by Carvalho et al. [57], which found that among a CVD sample, lower scores of resilience were associated with depressive symptoms and with female gender, compared to men. This finding could indicate that men tend to have more motivation to focus on problem solving coping strategies, whereas women tend to use emotion-focused coping strategies [11, 58]. Additionally, another study which assessed for depression using the CDS found a strong association between low resilience and depression (CDS $>95$ ) among CVD patients [59]. In our further analysis assessing mediation of resilience between PTSD and depression (CDS score), we found a significant effect for the interaction by resilience of the association between PTSD and depression (CDS score). We also found the difference in CDS score between those with low and high resilience decreased with increasing PTSD symptoms, potentially meaning that higher levels of PTSD partly override the protective effects of resilience. These findings suggest the need for intervention targets such as group cardiac rehabilitation and interventions to improve coping with adversities, which could ultimately reduce the risk of depression and strengthen resilience among cardiac patients. Furthermore, promoting physical activity among CVD patients 


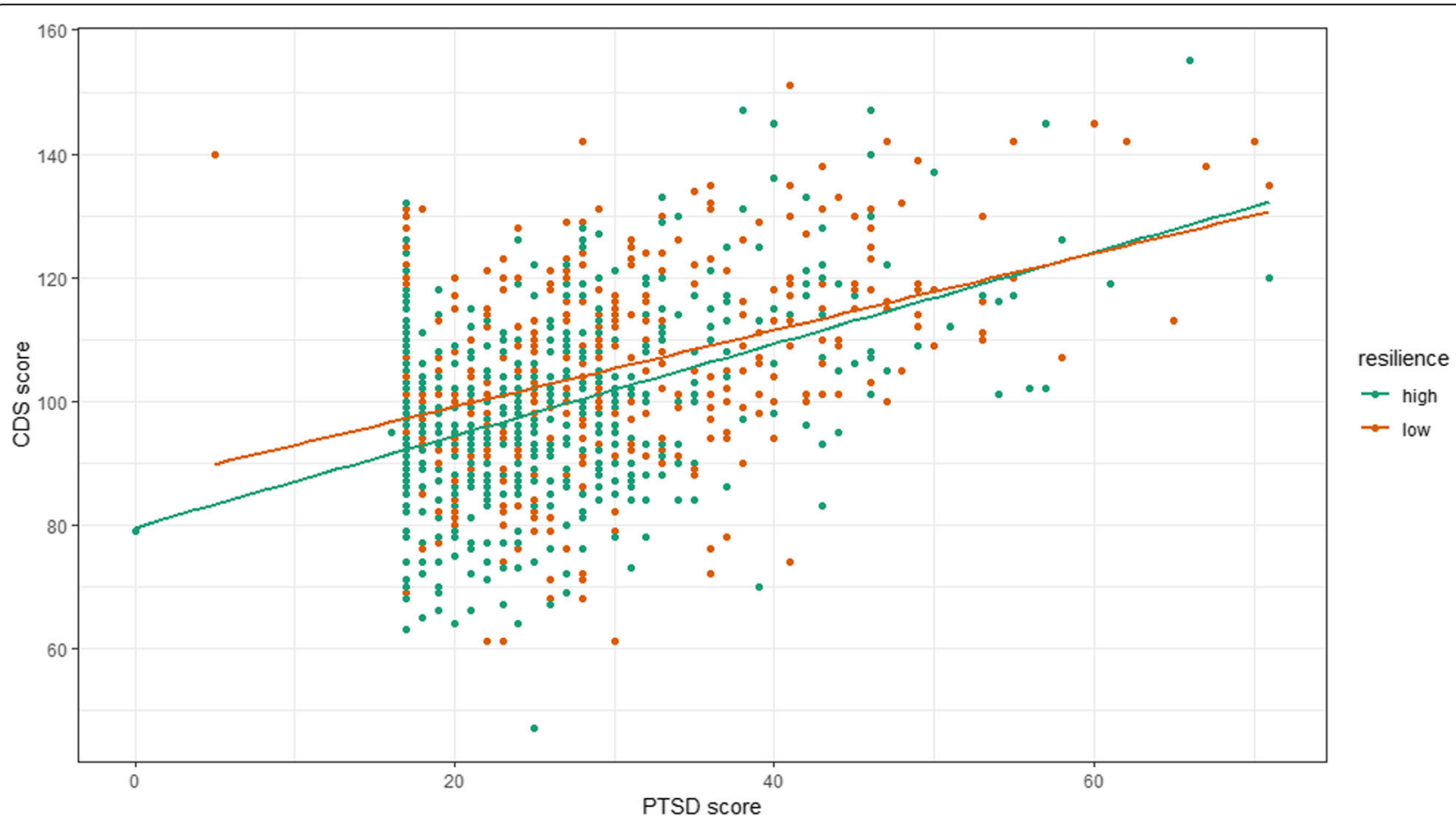

Fig. 3 Association of PTSD and CDS stratified by level of resilience. Note. CDS = Cardiac Depression Scale; PTSD = Post-traumatic stress disorder

is recommended as resilience also has been linked to exercise [60] and has been known to reduce the risk of depression among resilient patients with CVD [59].

Higher somatic symptoms were also associated with being female and higher depression levels in this study, consistent with previous reports which found females with major depression showed higher rates of somatic symptoms compared to men [61, 62]. A study conducted in Spain, which also used the PHQ-15 to assess for somatic symptoms, found women reported higher total scores than men and were more concerned in 8 out of 15 items of the PHQ-15 [63]. Nonetheless, these findings should be interpreted with caution since somatic symptom scales vary in different studies.

Our results also reveal that physical inactivity is associated with being female and higher depressive symptoms among our cardiac sample. It has been previously reported that female cardiac patients frequently engage in less exercise compared with their male counterparts, despite the increasing evidence to support the beneficial role of exercise among cardiac patients [64]. Physical inactivity has been associated with depression and has been shown to mediate the relationship between depression and cardiovascular events and mortality $[65,66]$. A recent systematic review found that depression could lead to a sedentary lifestyle and lower levels of physical activity [67]. These data along with our findings suggest that there is need for exercise programs for CVD patients, especially women and those with depression.
Furthermore, our findings shed light on gender differences for socioeconomic factors among men and women with both CVD and depressive symptoms. In the present study, and similar to other studies, women were more likely to be not married, unemployed, and less educated $[68,69]$, compared to men with CVD and comorbid depressive symptoms. These findings are supported by previous studies on $\mathrm{CHD}$ patients that female gender is linked to lower education, which increases the risk of onset of CHD [70], whereas employment and higher education play a protective role against depressive symptoms [71]. Those with high socioeconomic status have more self-esteem, more resources and social support, all of which reduce the stress that comes with depression compared to those with low socioeconomic status, whom have less access to social and personal resources, which increases stress levels. However, occupation and marital status were not significant in the final SEM and thus were not mediating effects of gender on depression (CDS score).

Furthermore, in our sample, women had more coexisting illnesses (i.e. diabetes and hypertension) compared with men with cardiac disease, a finding consistent with other studies [68, 69, 72]. There were no major differences in rates of angina as an initial cardiac diagnosis between men and women, which is inconsistent with results in other studies, which found higher angina rates among women compared with men $[73,74]$. 


\section{Strengths}

This study had several strengths. First, the high participation rate decreased the likelihood of selection and participation bias. Second, our sample of women was relatively large, compared to other studies, which provided sufficient statistical power for testing gender differences. Third, the CDS used in the study is the only psychometric scale suitable for the comparative depression assessment in heart disease patients, subjected to different interventions and has excellent properties for the diagnosis of severe depression, a score $>100$ having a sensitivity of $88 \%$ and a specificity of $84 \%$. Finally, the findings of our study are likely generalizable as our sample was recruited from four main hospitals of Nablus, Palestine, which provide cardiac care to a large percentage of individuals in the area.

\section{Limitations}

The limitations of our study are due to several sources. First, depression was not formally diagnosed by a psychological interview and was rather assessed using the CDS, thus we cannot conclude that our sample had clinical depression. However, the identification of certain mediating factors of gender on depression among cardiac patients can serve as a basis for developing the best intervention targeting depression among women and men with cardiac disease. Second, some patients were recruited at the time of admission and for the most part before receiving their intervention or diagnosis, and thus were under stress and anxiety. As some of the anxiety observed may have been transient, the level of depression and anxiety could have been overestimated. Finally, due to the cross-sectional design of the study the direction of associations cannot be derived with certainty and causality cannot be inferred.

\section{Conclusion}

This study demonstrated that, similar to the general population, the prevalence of severe depression is greater in female patients with cardiac disease compared to male patients. Overall, our findings provide new information documenting mediating factors, in particular PTSD, of the association between gender and depression among cardiac patients. These findings emphasize the need to devote more attention to identify and address potential mediating factors that could account for gender differences in depression. Providing supportive programs for female patients with CVD to improve their psychosocial well-being in cardiac rehabilitation seems of particular importance in conflict-prone areas, like Palestine.

\section{Additional files}

Additional file 1: Figure S1a, $\mathbf{1 b}$. SEM of the direct and indirect effects of gender on depression (CDS score) for age groups $<59(\mathrm{~N}=$ 500) and $\geq 59(N=522)$. (DOCX $140 \mathrm{~kb})$

Additional file 2: Figure S2. SEM of association between resilience, PTSD and depression (CDS score). (PNG 9 kb)

\section{Abbreviations}

BMI: Body mass index; CABG: Coronary artery bypass graft; CATH: Catheterization; CDS: Cardiac Depression Scale; CHD: Coronary heart disease; Cl: Confidence interval; CVD: Cardiovascular disease; DASS42: Depression Anxiety Stress Scale-42; DV: Dependent variable; EKNZ: Ethics Committee of Nordwest-und Zentral Schweiz; ENRICHD: Enhancing Recovery in Coronary Heart; ESSI: ENRICHD Social Support Instrument; HF: Heart failure; HS: High school; IRB: Institutional Review Board; IV: Independent variable; MCS: Mental Component Summary; MDD: Major depressive disorder; MI: Myocardial infarction; MOS: Medical Outcomes Survey; oPt: Occupied Palestinian territory; PCS: Physical Component Summary; PHQ-15: Patient Health Questionnaire-15; PTSD: Post-traumatic stress disorder; PTSD-PCL-S: Post-Traumatic Stress Disorder Checklist; QOL: Quality of life; RS-14: Resilience Scale-14; SD: Standard deviation; SE: Self-esteem; SEM: Structural equation model; SF-12: The 12-item Short Form Health Survey

\section{Acknowledgements}

We would like to acknowledge Ahmed Alkhayyat, Ahmad Hammoudi, Hiba Odeh, Jamil Shtayyeh, and Manal Taha who assisted in data collection, the staff at each of the hospitals who assisted in the recruitment process and the participants for giving their time to take part in the study.

\section{Authors' contributions}

HA conducted data collection, analyzed and interpreted data, and wrote the manuscript. AA and SHY supervised the data collection and the implementation of the study in Palestine and edited the manuscript. NPH, EZ, MK and CS participated in planning the data analysis. CS supervised the statistical analysis. NPH, EZ, MK and CS contributed to the interpretation of the results. NPH designed the study and directed its implementation. EZ directed the data analysis and interpretation of results. She edited all versions of the manuscript. All authors read and approved the final manuscript.

\section{Funding}

The study was funded by a Swiss Government Excellence Fellowship for Foreign Scholars (ESKAS) for the PhD student, HA, working on the project and by the Freiwillige Akademische Gesellschaft, Basel, Switzerland. The funders of the project took no part in the design of the study, data collection and analysis, interpretation of the data or the writing of the manuscript.

\section{Availability of data and materials}

The datasets used and/or analyzed during the current study are available from the corresponding author on reasonable request.

\section{Ethics approval and consent to participate}

This study was approved by the Ethics Committee of Nordwest- und Zentral Schweiz (EKNZ) in Basel, Switzerland and by the Institutional Review Board (IRB) committee at An-Najah National University in Nablus, Palestine. All patients enrolled in the study provided written informed consent.

\section{Consent for publication}

Not applicable.

\section{Competing interests}

The authors declare that they have no competing interests.

\section{Author details}

${ }^{1}$ Department of Epidemiology and Public Health, Swiss Tropical and Public Health Institute, Socinstrasse 57, P.O. Box, 4002, Basel, Switzerland. ${ }^{2}$ University of Basel, Petersplatz 1, 4001 Basel, Switzerland. ${ }^{3}$ Faculty of Medicine and 
Health Sciences, An-Najah National University, Rafidia Street, P.O. Box 7, Nablus, Palestine. ${ }^{4}$ An-Najah National University Hospital, Asira Street, Nablus, Palestine. ${ }^{5}$ School of Clinical Sciences, University of Bristol, 69 St Michael's Hill, Bristol BS2 8DZ, UK. Institute of Cardiovascular and Medical Sciences, Glasgow University, 126 University Place, Glasgow G12 8TA, UK.

Received: 16 March 2019 Accepted: 29 August 2019

Published online: 12 September 2019

\section{References}

1. Barth J, Schumacher M, Herrmann-Lingen C. Depression as a risk factor for mortality in patients with coronary heart disease: a meta-analysis. Psychosom Med. 2004;66:802-13.

2. Frasure-Smith $N$, Lesperance $F$. Recent evidence linking coronary heart disease and depression. Can J Psychiatr. 2006;51:730-7.

3. Lesperance F, Frasure-Smith N. Depression in patients with cardiac disease: a practical review. J Psychosom Res. 2000;48:379-91.

4. Nicholson A, Kuper $\mathrm{H}$, Hemingway $\mathrm{H}$. Depression as an aetiologic and prognostic factor in coronary heart disease: a meta-analysis of 6362 events among 146538 participants in 54 observational studies. Eur Heart J. 2006;27:2763-74.

5. Lett HS, Blumenthal JA, Babyak MA, Sherwood A, Strauman T, Robins C, Newman MF. Depression as a risk factor for coronary artery disease: evidence, mechanisms, and treatment. Psychosom Med. 2004;66:305-15.

6. Barrett-Connor E. Gender differences and disparities in all-cause and coronary heart disease mortality: epidemiological aspects. Best Pract Res Clin Endocrinol Metab. 2013;27:481-500

7. Lesperance F, Frasure-Smith N, Talajic M, Bourassa MG. Five-year risk of cardiac mortality in relation to initial severity and one-year changes in depression symptoms after myocardial infarction. Circulation. 2002;105:1049-53.

8. Piccinelli M, Wilkinson G. Gender differences in depression. Critical review. $\mathrm{Br}$ J Psychiatry. 2000;177:486-92.

9. Nolen-Hoeksema S, Larson J, Grayson C. Explaining the gender difference in depressive symptoms. J Pers Soc Psychol. 1999;77:1061-72.

10. Kornstein SG. Gender differences in depression: implications for treatment. J Clin Psychiatry. 1997;58(Suppl 15):12-8.

11. Möller-Leimkühler AM. Gender differences in cardiovascular disease and comorbid depression. Dialogues Clin Neurosci. 2007;9:71-83.

12. Krieger N. Genders, sexes, and health: what are the connections--and why does it matter? Int J Epidemiol. 2003;32:652-7.

13. Springer KW, Mager Stellman J, Jordan-Young RM. Beyond a catalogue of differences: a theoretical frame and good practice guidelines for researching sex/gender in human health. Soc Sci Med. 2012;74:1817-24.

14. Moller-Leimkuhler AM, Bottlender R, Strauss A, Rutz W. Is there evidence for a male depressive syndrome in inpatients with major depression? J Affect Disord. 2004;80:87-93.

15. Rahman O, Strauss J, Gertler P, Ashley D, Fox K. Gender differences in adult health: an international comparison. Gerontologist. 1994;34:463-9.

16. McDonough $P$, Walters $V$. Gender and health: reassessing patterns and explanations. Soc Sci Med. 2001:52:547-59.

17. Matthews S, Manor O, Power C. Social inequalities in health: are there gender differences? Soc Sci Med. 1999;48:49-60.

18. Mosca L, Barrett-Connor E, Wenger NK. Sex/gender differences in cardiovascular disease prevention: what a difference a decade makes. Circulation. 2011;124:2145-54.

19. Khan SS, Nessim S, Gray R, Czer LS, Chaux A, Matloff J. Increased mortality of women in coronary artery bypass surgery: evidence for referral bias. Ann Intern Med. 1990;112:561-7.

20. Penckofer SM, Holm K. Women undergoing coronary artery bypass surgery: physiological and psychosocial perspectives. Cardiovasc Nurs. 1990;26:13-8.

21. Naqvi TZ, Naqvi SS, Merz CN. Gender differences in the link between depression and cardiovascular disease. Psychosom Med. 2005;67(Suppl 1):S15-8.

22. Mickleborough LL, Takagi Y, Maruyama H, Sun Z, Mohamed S. Is sex a factor in determining operative risk for aortocoronary bypass graft surgery? Circulation. 1995:92:li80-4.

23. Shanmugasegaram S. Gender and sex differences in prevalence of major depression in coronary artery disease patients: a meta-analysis. Maturitas. 2012;73:305-11.

24. Kristofferzon ML, Lofmark R, Carlsson M. Myocardial infarction: gender differences in coping and social support. J Adv Nurs. 2003:44:360-74.
25. Mallik S, Spertus JA, Reid KJ, Krumholz HM, Rumsfeld JS, Weintraub WS, Agarwal P, Santra M, Bidyasar S, Lichtman JH, et al. Depressive symptoms after acute myocardial infarction: evidence for highest rates in younger women. Arch Intern Med. 2006;166:876-83.

26. Frasure-Smith N, Lesperance F, Juneau M, Talajic M, Bourassa MG. Gender, depression, and one-year prognosis after myocardial infarction. Psychosom Med. 1999;61:26-37.

27. Regitz-Zagrosek V, Oertelt-Prigione S, Prescott E, Franconi F, Gerdts E, ForystLudwig A, Maas AH, Kautzky-Willer A, Knappe-Wegner D, Kintscher U, et al. Gender in cardiovascular diseases: impact on clinical manifestations, management, and outcomes. Eur Heart J. 2016;37:24-34.

28. Vaccarino V, Abramson $J$, Veledar $E$, Weintraub WS. Sex differences in hospital mortality after coronary artery bypass surgery: evidence for a higher mortality in younger women. Circulation. 2002;105:1176-81.

29. Gruberg L, Beyar R. Women, coronary artery disease and percutaneous coronary intervention: still the same after all these years? Isr Med Assoc J. 2003:5:434-6.

30. Vaccarino V, Mallik S. 22 - Gender differences in the outcome of acute myocardial infarction. In: Legato MJ, editor. Principles of gender-specific medicine. San Diego: Academic; 2004. p. 224-33.

31. Wenger NK. Coronary heart disease: the female heart is vulnerable. Prog Cardiovasc Dis. 2003;46:199-229.

32. Czajkowski SM, Terrin M, Lindquist R, Hoogwerf B, Dupuis G, Shumaker SA, Gray JR, Herd JA, Treat-Jacobson D, Zyzanski S, Knatterud GL. Comparison of preoperative characteristics of men and women undergoing coronary artery bypass grafting (the post coronary artery bypass graft [CABG] biobehavioral study). Am J Cardiol. 1997;79:1017-24

33. Tulloch H, Greenman PS, Tasse V. Post-traumatic stress disorder among cardiac patients: prevalence, risk factors, and considerations for assessment and treatment. Behav Sci (Basel). 2014:5:27-40.

34. Ladwig KH, Baumert J, Marten-Mittag B, Kolb C, Zrenner B, Schmitt C. Posttraumatic stress symptoms and predicted mortality in patients with implantable cardioverter-defibrillators: results from the prospective living with an implanted cardioverter-defibrillator study. Arch Gen Psychiatry. 2008;65:1324-30.

35. Edmondson D, Richardson S, Falzon L, Davidson KW, Mills MA, Neria Y Posttraumatic stress disorder prevalence and risk of recurrence in acute coronary syndrome patients: a meta-analytic review. PLoS One. 2012;7:e38915.

36. O'Donnell ML, Creamer M, Pattison P. Posttraumatic stress disorder and depression following trauma: understanding comorbidity. Am J Psychiatry. 2004;161:1390-6.

37. Marie M, Hannigan $B$, Jones A. Mental health needs and services in the West Bank, Palestine. Int J Ment Health Syst. 2016;10(1):23.

38. Shi WY, Stewart AG, Hare DL. Major depression in cardiac patients is accurately assessed using the cardiac depression scale. Psychother Psychosom. 2010;79:391-2

39. Wise FM, Harris DW, Carter LM. Validation of the cardiac depression scale in a cardiac rehabilitation population. J Psychosom Res. 2006;60:177-83.

40. Blanchard EB, Jones-Alexander J, Buckley TC, Forneris CA. Psychometric properties of the PTSD checklist (PCL). Behav Res Ther. 1996;34:669-73.

41. The ENRICHD investigators. Enhancing recovery in coronary heart disease patients (ENRICHD): study design and methods. Am Heart J. 2000;139:1-9.

42. Enhancing recovery in coronary heart disease (ENRICHD) study intervention: rationale and design. Psychosom Med. 2001;63:747-55.

43. Wagnild GMGP. The resilience scale user's guide: for the U.S. English version of the resilience scale TM and the 14-item resilience scale TM (RS-14 TM): Resilience Center; 2009.

44. Robins RW, Hendin HM, Trzesniewski KH. Measuring global self-esteem: construct validation of a single-item measure and the Rosenberg self-esteem scale. Personal Soc Psychol Bull. 2001;27:151-61.

45. Ware J Jr, Kosinski M, Keller SD. A 12-item short-form health survey: construction of scales and preliminary tests of reliability and validity. Med Care. 1996;34:220-33.

46. Kroenke K, Spitzer RL, Williams JB. The PHQ-15: validity of a new measure for evaluating the severity of somatic symptoms. Psychosom Med. 2002;64:258-66.

47. Allabadi H, Alkaiyat A, Alkhayyat A, Hammoudi A, Odeh H, Shtayeh J, Taha M, Schindler C, Zemp E, Haj-Yahia S, Probst-Hensch N. Depression and anxiety symptoms in cardiac patients: a cross-sectional hospital-based study in a Palestinian population. BMC Public Health. 2019;19:232.

48. Cole SR, Hernan MA. Fallibility in estimating direct effects. Int J Epidemiol. 2002;31:163-5. 
49. Dao TK, Chu D, Springer J, Gopaldas RR, Menefee DS, Anderson T, Hiatt E, Nguyen Q. Clinical depression, posttraumatic stress disorder, and comorbid depression and posttraumatic stress disorder as risk factors for in-hospital mortality after coronary artery bypass grafting surgery. J Thorac Cardiovasc Surg. 2010;140:606-10.

50. Kao CW, Chen TY, Cheng SM, Lin WS, Friedmann E, Thomas SA. Gender differences in the predictors of depression among patients with heart failure. Eur J Cardiovasc Nurs. 2014;13:320-8.

51. Frasure-Smith $\mathrm{N}$, Lesperance $\mathrm{F}$. Reflections on depression as a cardiac risk factor. Psychosom Med. 2005;67(Suppl 1):S19-25.

52. National Institute of Mental Health. The numbers count: mental disorders in America. Bethesda: National Institute of Mental Health; 2006.

53. Cohen GH, Sampson LA, Fink DS, Wang J, Russell D, Gifford R, Fullerton C, Ursano R, Galea S. Gender, position of authority, and the risk of depression and posttraumatic stress disorder among a National Sample of U.S. reserve component personnel. Womens Health Issues. 2016;26:268-77.

54. Horesh D, Lowe SR, Galea S, Uddin M, Koenen KC. Gender differences in the long-term associations between posttraumatic stress disorder and depression symptoms: findings from the Detroit neighborhood health study. Depress Anxiety. 2015;32:38-48.

55. Nolen-Hoeksema S. Sex differences in unipolar depression: evidence and theory. Psychol Bull. 1987;101:259-82.

56. Van de Velde S, Bracke P, Levecque K. Gender differences in depression in 23 European countries. Cross-national variation in the gender gap in depression. Soc Sci Med. 2010;71:305-13.

57. Carvalho IG, Bertolli EDS, Paiva L, Rossi LA, Dantas RAS, Pompeo DA. Anxiety, depression, resilience and self-esteem in individuals with cardiovascular diseases. Rev Lat Am Enfermagem. 2016;24:e2836.

58. Bazrafshan M-R, Jahangir F, Mansouri A, Kashfi SH. Coping strategies in people attempting suicide. Int J High Risk Behav Addict. 2014;3:e16265.

59. Toukhsati SR, Jovanovic A, Dehghani S, Tran T, Tran A, Hare DL. Low psychological resilience is associated with depression in patients with cardiovascular disease. Eur J Cardiovasc Nurs. 2017;16:64-9.

60. Fleshner M, Maier SF, Lyons DM, Raskind MA. The neurobiology of the stress-resistant brain. Stress. 2011;14:498-502.

61. Dessotte CAM, Silva FS, Furuya RK, Ciol MA, Hoffman JM, Dantas RAS. Somatic and cognitive-affective depressive symptoms among patients with heart disease: differences by sex and age. Rev Lat Am Enfermagem. 2015;23:208-15.

62. Dekker J, Koelen JA, Peen J, Schoevers RA, Gijsbers-van Wijk C. Gender differences in clinical features of depressed outpatients: preliminary evidence for subtyping of depression? Women Health. 2007;46:19-38.

63. Gonzalez DS, Rodriguez M, Garcia C, Prieto R, Saiz-Ruiz J. Gender differences in major depressive disorder: somatic symptoms and quality of life. Rev Psiquiatr Salud Ment. 2009;2:119-27.

64. Hunt-Shanks T, Blanchard C, Reid RD. Gender differences in cardiac patients: a longitudinal investigation of exercise, autonomic anxiety, negative affect and depression. Psychol Health Med. 2009;14:375-85.

65. Bonnet F, Irving K, Terra JL, Nony P, Berthezene F, Moulin P. Anxiety and depression are associated with unhealthy lifestyle in patients at risk of cardiovascular disease. Atherosclerosis. 2005:178:339-44.

66. Whooley MA, de Jonge P, Vittinghoff E, Otte C, Moos R, Carney RM, Ali S, Dowray S, Na B, Feldman MD, et al. Depressive symptoms, health behaviors, and risk of cardiovascular events in patients with coronary heart disease. JAMA. 2008;300:2379-88.

67. Roshanaei-Moghaddam B, Katon WJ, Russo J. The longitudinal effects of depression on physical activity. Gen Hosp Psychiatry. 2009;31:306-15.

68. Vaccarino V, Lin ZQ, KasI SV, Mattera JA, Roumanis SA, Abramson JL, Krumholz HM. Gender differences in recovery after coronary artery bypass surgery. J Am Coll Cardiol. 2003;41:307-14.

69. Doering LV, McKinley S, Riegel B, Moser DK, Meischke H, Pelter MM, Dracup K. Gender-specific characteristics of individuals with depressive symptoms and coronary heart disease. Heart Lung. 2011;40:e4-14.

70. Thurston RC, Kubzansky LD, Kawachi I, Berkman LF. Do depression and anxiety mediate the link between educational attainment and CHD? Psychosom Med. 2006;68:25-32.

71. Bjerkeset $\mathrm{O}$, Nordahl HM, Mykletun A, Holmen J, Dahl AA. Anxiety and depression following myocardial infarction: gender differences in a 5-year prospective study. J Psychosom Res. 2005;58:153-61.
72. Anand SS, Xie CC, Mehta S, Franzosi MG, Joyner C, Chrolavicius S, Fox KA, Yusuf S. Differences in the management and prognosis of women and men who suffer from acute coronary syndromes. J Am Coll Cardiol. 2005;46:1845-51.

73. Daly C, Clemens F, Lopez Sendon JL, Tavazzi L, Boersma E, Danchin N, Delahaye F, Gitt A, Julian D, Mulcahy D, et al. Gender differences in the management and clinical outcome of stable angina. Circulation. 2006;113:490-8.

74. Milner KA, Funk M, Arnold A, Vaccarino V. Typical symptoms are predictive of acute coronary syndromes in women. Am Heart J. 2002;143:283-8.

\section{Publisher's Note}

Springer Nature remains neutral with regard to jurisdictional claims in published maps and institutional affiliations.

\section{Ready to submit your research? Choose BMC and benefit from:}

- fast, convenient online submission

- thorough peer review by experienced researchers in your field

- rapid publication on acceptance

- support for research data, including large and complex data types

- gold Open Access which fosters wider collaboration and increased citations

- maximum visibility for your research: over $100 \mathrm{M}$ website views per year

At BMC, research is always in progress.

Learn more biomedcentral.com/submissions 